\title{
A militarização dos presídios brasileiros
}

Leticia Maria Schabbach*

http://orcid.org/0000-0002-1828-6030

Introdução

O Brasil ocupa o terceiro lugar entre os países com maior número de presos (total de 726.712 em 2016), sendo superado apenas pela China (1.649.804) e pelos Estados Unidos (2.145.100) (World Prison Brief, 2016). Deste contingente, 36.765 (5\%) encontravam-se sob custódia nas carceragens de delegacias de polícia, 689.517 (95\%) cumpriam pena em um dos 1.418 estabelecimentos estaduais e 437 em um dos quatro presídios ${ }^{1}$ federais em funcionamento em 2016, conforme os registros do Levantamento Nacional de Informações Penitenciárias (Brasil, 2017). A taxa de ocupação (número de presos em relação às vagas) era de 197,4\% (quase dois presos por vaga), e a de aprisionamento, 352,6 presos por 100 mil habitantes.

No país, de 1990 (total de 90 mil presos) para 2016 a população carcerária cresceu 707\% (Brasil, 2017). Não se trata de uma exclusividade brasileira, pois tal crescimento acompanha tendência mundial de ampliação do encarceramento desde a década de 1990, que foi constatada por autores como Bauman (1999), Wacquant

* Universidade Federal do Rio Grande do Sul, Porto Alegre, Brasil.

1. Neste trabalho o termo "presídio" é utilizado alternadamente com "cadeia”, "prisão", "cárcere”, "penitenciária", ainda que existam diferenças terminológicas e jurídicas entre os termos (Brasil, 1984). Para os nossos propósitos aqui, todas essas expressões referem-se às unidades ou estabelecimentos onde indivíduos cumprem pena privativa de liberdade (já condenados) ou foram privados da liberdade enquanto aguardam o trânsito em julgado do processo judicial (presos provisórios). 
(2001) e Garland (2008). Para Garland (2008), este movimento estaria vinculado à crise do previdenciarismo penal (paradigma que encarava o crime como produto de processos causais e o criminoso como objeto de análise e de intervenção correcional) e da crença liberal na capacidade de reabilitação e reinserção social do cárcere.

Os estudos sobre prisões e presos no âmbito das Ciências Sociais iniciaram na década de 1980 no país, dentro de um conjunto de análises mais gerais sobre violência e criminalidade. Estas últimas foram se distanciando do enfoque anterior, centrado na violência cometida pelo Estado contra grupos políticos. Especificamente quanto aos estudos prisionais, foram pioneiros os livros: $O$ mundo do crime: a ordempelo avesso, de José Ricardo Ramalho (1979), sobre a Casa de Detenção de São Paulo; Cemitério dos vivos: análise sociológica de uma prisão de mulheres, de Julita Lemgruber (1983), pesquisa desenvolvida na Penitenciária Feminina Talavera Bruce na cidade do Rio de Janeiro; e as duas versões do livro A oficina do diabo, de Edmundo Campos Coelho $(1987,2005)$, que tratam do sistema penitenciário do Rio de Janeiro.

Nesse mesmo período, após um amplo debate no meio jurídico sobre a situação do sistema penitenciário brasileiro, foi promulgada a vigente Lei de Execução Penal - LEP (Brasil, 1984). Essa lei estabeleceu diretrizes nacionais à política criminal e penitenciária, mas atribuindo a cada governo estadual a responsabilidade pela configuração do seu próprio sistema penitenciário, ainda que submetido à correição e à supervisão do Poder Judiciário.

Entre as décadas de 1990 e 2000 os estudos prisionais ampliaram-se (não apenas nas ciências sociais, também no âmbito do direito e das ciências da saúde, como informa Salla, 2017), muitos deles impulsionados pelas rebeliões e assassinatos de prisioneiros pelas forças policiais (a exemplo do Massacre de Carandiru, em 1992). Inicialmente houve uma diversificação dos tópicos abordados, que passaram a incluir as condições de aprisionamento, o trabalho prisional, o movimento de privatização, a violência institucional etc. Novas questões surgiram a partir de 2000, tais como: a expansão das políticas de encarceramento, as prisões de mulheres, as religiões e a educação na prisão, as facções criminosas, as relações de poder, a atuação dos profissionais nos presídios (Salla, 2017; Lourenço e Alvarez, 2017).

Em síntese, os resultados desses trabalhos convergem no reconhecimento dos principais problemas existentes: superlotação, deterioração das condições de habitabilidade e de desempenho profissional dos agentes penitenciários, precariedade dos serviços ofertados (educação, trabalho, saúde etc.), descumprimento da LEP, dificuldade de reinserção social do egresso, fortalecimento dos grupos criminosos e seu efeito sobre o controle e a gestão penitenciária. Ao mesmo tempo, conforme constatado por Salla (2017) e Lourenço e Alvarez (2017), são poucas as abordagens sobre o cotidiano prisional e os profissionais que atuam nas prisões. 
De acordo com os dados de 2016 constantes no Relatório do Infopen (BRASIL, 2017, p. 46), existiam 105.2015 profissionais em atividade no sistema prisional brasileiro, representado um aumento de $42 \%$ em relação a 2008. Destes, 78.163 (74\%) ocupavam o cargo de "servidor voltado à atividade de custódia", sejam agentes penitenciários ou agentes de cadeia pública. Além deles, havia os profissionais da área da saúde e educação (10.955, 10\% do total de servidores), os lotados em cargos administrativos $(8.900,8 \%)$, os policiais militares em atividade exclusiva no estabelecimento prisional $(3.260,3 \%)$, outros trabalhadores $(3.034,3 \%)$, os advogados (723, 1\%), e os policiais civis em atividade exclusiva no estabelecimento prisional (180, menos de $1 \%)$.

Esse contingente de servidores é responsável por uma ampla gama de atividades de média complexidade que vão do planejamento, organização e execução de serviços de vigilância, custódia e segurança de infratores recolhidos em estabelecimentos prisionais até a realização de programas e ações de apoio ao tratamento penal para sua ressocialização (Jaskowiak e Fontana, 2015).

Outras características demonstram que, do total de servidores, $74 \%$ são homens, e quanto ao regime jurídico, $75 \%$ são efetivos, $18 \%$ temporários, $5 \%$ terceirizados e $2 \%$ comissionados. As mulheres representam $26 \%$ do total, superando quantitativamente os homens na área da saúde e educação (69\%); advogadas (53\%) e em cargos administrativos (51\%). Em contrapartida, no grupo mais numeroso dos servidores voltados às atividades de custódia elas representam apenas $18 \%$ do total (Brasil, 2017).

Este artigo examina a atuação dos policiais militares nas prisões, historicamente responsáveis pela vigilância externa das unidades penais (muros, torres, portões) ou, se oficiais, eventualmente designados para cargos diretivos (Universidade de São Paulo, 1995). A sua presença nas prisões é encontrada na maioria dos estados brasileiros (dezoito unidades federativas), em uma espécie de "militarização" do sistema prisional, onde passaram a se responsabilizar por atividades administrativas e de controle interno, para além da vigilância dos limites externos dos estabelecimentos.

$\mathrm{Na}$ contramão dessa tendência, entretanto, em alguns estados se verifica uma redução ou mesmo a não contratação desses profissionais, devido à criação de cargos específicos para substituí-los na vigilância externa e com o uso de armas de fogo, como o de "agente de escolta e muralha" existente no estado de São Paulo (Sabaini, 2009).

A militarização do sistema prisional é criticada por Salla (2017), que a considera uma consequência nefasta da perda de controle e de autoridade da administração prisional frente ao aumento da população carcerária e do poder do contingente prisional, além de ser uma tendência contrária aos preceitos da LEP.

Além do acima citado, não foram encontrados outros estudos sobre esse grupo de profissionais. As raras publicaçóes sobre trabalhadores prisionais privilegiam os 
agentes penitenciários, em detrimento daqueles cuja participação no dia a dia do cárcere é quantitativamente menor.

Este artigo propõe uma reflexão sobre as outras categorias profissionais atuantes nas prisões brasileiras, enfocando-se a presença dos policiais militares, a sua distribuição pelas unidades federativas, bem como a ampliação das atividades por eles desempenhadas. Também são examinadas as características das unidades prisionais associadas à existência, mais ou menos frequente, dos policiais militares, e que levam os governos estaduais a adotar tal estratégia de contratação de pessoal dentro de sua política penitenciária.

Para dar conta desses objetivos, utilizou-se abordagem quantitativa a partir de informações secundárias cadastradas no Infopen e gerenciadas pelo Departamento Penitenciário Nacional (Depen) do então Ministério da Segurança Pública. Em específico, foi acessada, em dezembro de 2018, a base de microdados referente a 2016 (o último ano divulgado à época, Brasil, 2016) e o correspondente Relatório Sintético (Brasil, 2017), existentes no sítio eletrônico: http://depen.gov.br/DEPEN/depen/ sisdepen/infopen. $\mathrm{Na}$ organização e exame dos dados, contou-se com a estatística descritiva, a análise correlacional e a de regressão, por meio dos softwares Excel ${ }^{\circledR} \mathrm{e}$ Statistical Package for the Social Sciences (SPSS ${ }^{\circ}$ ). Também se realizou uma revisão bibliográfica sobre os estudos que tratam dos funcionários prisionais, a fim de se conhecerem o escopo das pesquisas, o(s) grupo(s) profissional(is) contemplados e os principais resultados. Este estado da arte, que fundamenta as análises empíricas subsequentes, é apresentado a seguir.

\section{Os estudos sobre os trabalhadores das prisões}

Ao analisar os estudos prisionais produzidos ao longo de uma trajetória de mais de vinte anos, Salla (2017) cita um único trabalho sobre os funcionários, a dissertação de mestrado de Lopes (1998), Atualidades do discurso disciplinar: a representação da disciplina e do disciplinar na fala dos agentes de segurança penitenciária, baseada em pesquisa com 21 agentes de segurança de oito unidades do estado de São Paulo, e que, mais tarde, foi publicada como artigo (Lopes, 2002). Nesse trabalho Lopes examina os efeitos nocivos do trabalho dos agentes: alterações comportamentais (uso de álcool e drogas psicotrópicas), práticas ilícitas, desgaste físico e mental frente à superlotação e ao reduzido quadro funcional. Já Lourenço e Alvarez (2017) apresentaram quatro dissertações de mestrado produzidas nos estados do Amazonas (Siqueira, 2016), da Bahia (Monteiro, 2013), da Paraíba (Sarmento, 2014) e de São Paulo (Sabaini, 2012) e uma tese desenvolvida em São Paulo (Reis, 2012). 
Embora não constem nas revisões bibliográficas acima mencionadas, três autores brasileiros, a seguir apresentados, são referências importantes entre os estudos sobre trabalhadores prisionais, especialmente os agentes penitenciários. O primeiro deles é Luiz Antônio Bogo Chies, que, em pesquisa sob a sua coordenação (Chies et al., 2001), examinou o processo social de inserção e assimilação do cotidiano carcerário por esses trabalhadores, tendo como universo empírico o Presídio Regional de Pelotas no Rio Grande do Sul, onde contatou (com aplicação de questionário) 33 agentes penitenciários. Alguns anos mais tarde, Pedro Rodolfo Bodê de Moraes (2005) investigou unidades prisionais da região metropolitana de Curitiba, no Paraná, com o intuito de conhecer o processo de construção da identidade de agentes penitenciários a partir da dinâmica prisional e de sua relação com a sociedade mais ampla. O livro é baseado em sua tese de doutorado defendida no Instituto Universitário de Pesquisas do Rio de Janeiro, cujas conclusões foram mais tarde retomadas em artigo (Moraes, 2013). A publicação mais recente a ser destacada é a de Luiz Claudio Lourenço (2010), que entrevistou 91 agentes penitenciários da Região Metropolitana de Belo Horizonte, em Minas Gerais, a fim de descrever a categoria profissional, considerada pouca conhecida e mal compreendida.

Estes três estudos ensejaram desdobramentos posteriores, que, partindo dos mesmos enfoques teóricos, ampliaram o escopo empírico da temática, como se verificará a seguir.

A monografia de Santos (2007) envolveu aplicação de questionário a um grupo de agentes que frequentaram curso de atualização na Escola Penitenciária do Paraná, em 2005, e outros funcionários lotados em duas unidades penais paranaenses, totalizando 564 entrevistados. O seu objetivo foi identificar a ocorrência do fenômeno da "prisionização" enquanto um processo diferenciado de socialização que acomete, além dos presos, o grupo de funcionários, principalmente os agentes penitenciários.

Por meio de pesquisa em dois presídios de Itirapina, município do interior do estado de São Paulo, com a realização de entrevistas com agentes de segurança, o estudo de Sabaini (2009) pretendeu investigar as relações hierárquicas estabelecidas entre eles e os presos, bem como a construção da identidade desses trabalhadores. $\mathrm{O}$ autor salienta que, diferentemente das conclusões de estudos desenvolvidos em outras localidades, o agente penitenciário ébem visto pela sociedade daquele pequeno município paulista, sendo que lá a profissão é valorizada porque remunera melhor do que as outras oportunidades de emprego disponíveis aos jovens concluintes do ensino médio.

Silveira (2009) realizou investigação junto a agentes penitenciários do Departamento Penitenciário do estado do Paraná, reunindo informações de quarenta encontros de grupos operativos ocorridos entre 2001 e 2002, dentro de uma pro- 
posta de pesquisa e de intervenção (terapêutica) focada nas angústias decorrentes da prática profissional.

A pesquisa executada por Jaskowiak e Fontana (2015), com base em informações oriundas de entrevistas com 26 agentes penitenciários lotados no presídio regional de Santo Ângelo, município do Rio Grande do Sul, buscou conhecer as condições de trabalho e os reflexos da atividade laboral sobre a saúde dos profissionais.

Ferreira e Sousa (2015) contataram 25 agentes penitenciários que frequentaram um curso de atualização na Escola Penitenciária de Tocantins, e, usando o diário de campo como instrumento de coleta, almejaram compreender os sentidos atribuídos ao cotidiano de trabalho, enquanto fonte de estigma e de estresse.

Em síntese, além de citarem obras de referência sobre a realidade carcerária (Clemmer, 1940; Goffman, 1974; Thompson, 1980; Foucault, 1986; Coelho, 1987, 2005, entre outras), os autores que tematizam os trabalhadores das prisões empregam conceitos e hipóteses muito próximas, que são, em geral, validados por seus achados empíricos. É pertinente, pois, destacar alguns desses enfoques e conclusões.

$\mathrm{Na}$ maioria dos estudos é referido o conceito de instituição total de Goffman (1974) para designar a instituição prisional enquanto local de residência e de trabalho marcado pela segregação social e pelo isolamento durante um período considerável de tempo. Não obstante, alguns autores lançam mão de outras categorias, a saber: sistema social penitenciário caracterizado pela complexidade (Chies et al., 2001); regime interno próprio e ambiente particular (Thompson, 1980; Silveira, 2009); um tipo de organização social (Moraes, 2005). Para alguns desses pesquisadores a prisão não seria uma instituição total propriamente dita, visto que presos e funcionários mantêm relações extramuros (com a família, amigos, colegas), vínculos também impactados pela vivência prisional (Chies et al., 2001; Sabaini, 2009; Silveira, 2009; Lourenço, 2010). No tocante aos aspectos de vigilância e disciplina, para Lourenço (2010) a prisão não funcionaria como panóptico ideal, mas como dispositivo invertido, porque, ao contrário do que se supõe, são os presos que vigiam os agentes em seus padrões regulares de atuação. A existência de uma dupla vigilância (presos-funcionários) é salientada por Chies et al. (2001), Santos (2007) e Sabaini (2009), este último defendendo, em acréscimo, que é a instituição que se molda aos reclusos e não o contrário.

Percebe-se um consenso entre os autores quanto aos efeitos causados pela experiência prisional no comportamento tanto dos indivíduos que cumprem ou aguardam a sua pena quanto dos que trabalham no cárcere. Trata-se do processo denominado por Clemmer (1940) de prisionização², conceito aplicado originalmente aos presos,

2. Acrescentam-se a esse termo categorias similares utilizadas pelos autores consultados: prisionalização, processo especial de socialização ou novo processo de interação social (Chies et al., 2001; Silveira, 2009; 
mas estendido aos trabalhadores prisionais, porém, em menor grau e intensidade, na medida em que eles transitam livremente entre os ambientes interno e externo das prisões. Embora essa espécie de socialização envolva diferentes contextos e intensidades (variando, por exemplo, entre os tipos de regime: fechado, semiaberto, aberto), o seu traço comum é a assimilação de comportamentos, hábitos e valores característicos da instituição prisional.

Ao se inserir no ambiente prisional, o preso sofre uma transformação, de interno para cativo da "sociedade de cativos" (Coelho, 1987, p. 63): "basta que se tornem membros competentes desta sociedade sui generis, observando seus códigos, valores e normas e hábitos e aprendendo a gramática de sua articulação. É um duro e perigoso aprendizado ao fim do qual o indivíduo terá perdido sua identidade anterior”. Esse processo estende-se aos funcionários, embora com menor vigor, como já referido. Da mesma forma que o preso, o funcionário vivenciaria o processo de "tirar cadeia", expressão resgatada da gíria dos detentos por autores como Ramalho (1979, p. 102) e Coelho (1987, p. 63).

Entretanto, mesmo que se aplique a todos os grupos profissionais (Rudnicki, 1999; Chies et al., 2001; Silveira, 2009), os processos e mecanismos acima destacados atingem com mais força os agentes penitenciários, que trabalham em contato direto e mais prolongado com os presos, geralmente em regime de plantões. São principalmente estes os submetidos à "prisionalização sem punição" (Chies et al., 2001, p. 108), que trabalham "presos com os presos" (Moraes, 2005, p. 221), que "representam a última barreira de contato social e a mão do Estado na aplicação das sentenças" (Lourenço, 2010, p. 16); enfim, os que, entre os diferentes grupos profissionais, mais estão imersos na cultura e dinâmica prisionais.

Por outro lado, o estigma social que caracteriza as prisões e acompanha os presos também se aplicaria aos agentes penitenciários (e demais funcionários), constituindo uma das razões pelas quais esses profissionais são pouco valorizados enquanto categoria. Lourenço (2010) discorre sobre o duplo estigma que envolve os "responsáveis pelo controle e vigilância de [...] indivíduos indesejáveis" (Idem, p. 14), verificado na sociedade (em que são percebidos como desacreditáveis, corruptos, contaminados pelo ambiente prisional) e na prisão (por conta da hostilidade e do desprezo dos presos para com eles). Na visão de Moraes (2005), os agentes penitenciários ocupam uma posição ambígua que transita entre dois mundos: o da lei/ordem e o do crime/

Ferreira e Sousa, 2015); processo de institucionalização (Lourenço, 2010); carcerização - efeito deteriorante que incide sobre os operadores das agências penais e gera um estresse contínuo (Zaffaroni, 1991); assimilação de comportamentos ou processo de socialização diferenciado (Santos, 2007) ou acelerado (Moraes, 2005); fabricação de indivíduos (Sabaini, 2009); familiarização (Moraes, 2005; Ferreira e Sousa, 2015). 
desordem. Por decorrência, a sua situação seria mais vulnerável do que a dos presos, na medida em que são alvos diretos de sua hostilidade, ao representarem o sistema que os oprime (Coelho, 1987; Silveira, 2009).

Acrescenta-se a isso a concentração de poder entre os presos, que vem mudando as relações entre eles e o staff, o que faz com que, diante das falhas na manutenção da ordem e do número reduzido de funcionários, os presos mais poderosos passem a impor as regras de existência dentro das prisões e estabeleçam novas dinâmicas que acabam reduzindo o poder e a autoridade dos agentes penitenciários e dos demais funcionários (Salla, 2017).

Trata-se de uma profissão arriscada, mal remunerada e estressante que produz distúrbios físicos e psíquicos (dentre eles, ansiedade e depressão) e restrição de lazer (Lourenço, 2010), insatisfação e desgaste emocional (Jaskowiak e Fontana, 2015), sensação de insegurança e comportamento agressivo (Santos, 2007), efeitos que ultrapassam o ambiente prisional, atingindo em diversos graus as relações sociais adjacentes. E também, conforme Moraes (2013), a fim de não demonstrarem fraqueza, eles não podem revelar qualquer sofrimento (físico ou psíquico) individual.

No entanto, a profissionalização do agente penitenciário trouxe maior escolaridade e a possibilidade legal de portar arma funcional (Brasil, 2014). Além disto, em dezembro de 2019 foi aprovada a emenda constitucional n. 104 (Brasil, 2019), que cria as polícias penais federal, estaduais e distrital.

\section{A presença dos policiais militares nos sistemas penitenciários estaduais e nas unidades prisionais}

Os policiais militares em atuação exclusiva nos presídios totalizavam, em 2016,3.260 funcionários, 3\% do total de servidores. Dentre eles, apenas 227 eram mulheres (7\%) (Brasil, 2017).

O gráfico 1 apresenta a participação (em percentuais) dos policiais militares e dos agentes penitenciários nos sistemas penitenciários dos estados brasileiros (com exceção do Rio de Janeiro, para o qual não havia a informação sobre a quantidade de agentes penitenciários). Verifica-se uma associação nítida, em sentido negativo, entre a presença de policiais militares e a de agentes penitenciários, atingindo coeficiente de correlação de Pearson de $-0,894$ e significância de $0,000^{3}$. Ou seja, presídios com maior número de agentes tendem a possuir relativamente menos policiais militares,

3. O coeficiente de correlação de Pearson mede o grau de correlação (em sentido negativo ou positivo) entre duas variáveis. Já a significância é um teste que avalia se a hipótese nula pode ser rejeitada e a principal confirmada, utilizando-se como parâmetro valores menores ou iguais a 0,05. 
GRÁFICO 1

Distribuição da Participação dos Agentes Penitenciários e dos Policiais Militares sobre o Total de Profissionais em Atividade nas Unidades Prisionais Estaduais, Brasile Estados, Dados de Junho de 2016

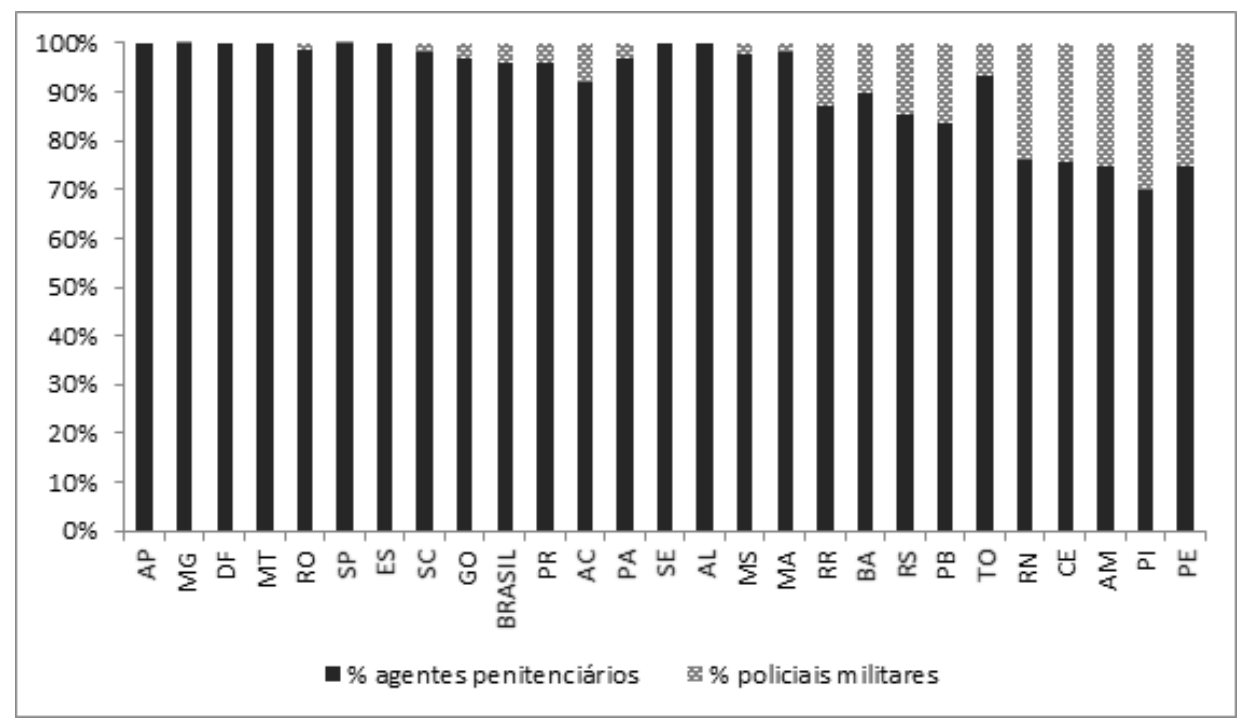

Fonte: Brasil (2017, p. 46). Elaboração própria.

e vice-versa. Pode-se afirmar, portanto, que os policiais militares estão assumindo outros encargos dentro dos presídios, inclusive o controle interno, até recentemente executado apenas pelos servidores em atividade de vigilância.

Quanto à distribuição dos policiais militares nos estados, percebem-se nitidamente dois polos, abaixo e acima da média nacional de participação (3\% em relação ao conjunto de funcionários). Nos estados de Alagoas, Amapá, Espírito Santo, Mato Grosso, Rio de Janeiro, Sergipe, Minas Gerais e no Distrito Federal, não há policiais militares trabalhando em prisões, provavelmente porque foram substituídos por outros cargos civis, em especial para a função de vigilância externa das unidades. Em contrapartida, os estados do Piauí, Rio Grande do Norte, Ceará, Amazonas, Pernambuco, Paraíba, Rio Grande do Sul, Roraima, Bahia e Acre situam-se acima da média nacional, com maior participação de policiais militares em presídios, onde provavelmente estejam desempenhando um rol maior de funções, para além da recorrente vigilância externa. Os outros estados aproximam-se do percentual nacional.

Considerando-se que a alocação de policiais militares em presídios é uma opção de política penitenciária adotada (ou não) pelos governos estaduais, questiona-se: a) Quais características das unidades prisionais pesam nessa tomada de decisão? Será que a localização dos presídios, o número de presos, a superlotação, o tipo de regime ou de situação jurídica (presos provisórios versus condenados), o tipo de crime mais 
frequente, a presença de outros servidores e a frequência de visitas seriam fatores preditivos da adoção ou não de tal política?

Para responder a ambas as indagações, recorreu-se à base de microdados do Infopen (Brasil, 2016),já mencionada, que dispunha em planilha eletrônica $\left(\right.$ Excel $\left.^{\circ}\right) 1.453$ unidades de análise, representadas pelos estabelecimentos penais, e 1.121 variáveis que foram submetidas a uma organização e seleção de acordo com a sua pertinência para o estudo. Vários ajustes, a seguir detalhados, foram efetuados na base original a fim de adequá-la aos propósitos do estudo. Em primeiro lugar, foram excluídos 31 casos sem qualquer informação referente às variáveis, chegando-se a um total de 1.422 presídios. Na sequência, para a constituição de uma amostra homogênea de casos, retiraram-se as quatro penitenciárias federais e 148 presídios estaduais que não continham dados específicos sobre funcionários. Do total de 1.270, excluíram-se, ainda, dois casos inverossímeis que registraram dois ou mais policiais militares por preso. Após essas alterações, a base final do estudo passou a contar com 1.268 unidades prisionais estaduais e 22 variáveis (as de identificação, as dependentes e as independentes).

Com relação à presença de policiais militares, a distribuição pelas casas prisionais demonstrou que a grande maioria delas $(971,77 \%)$ não contava com esses profissionais no seu quadro funcional. Portanto, se houve um movimento de militarização do sistema penitenciário brasileiro, ele não foi abrangente; pelo contrário, em apenas 297 (23\%) das instituições havia a participação dos mesmos. Isso torna bastante peculiar a utilização dessa política de provisão de pessoal pelos governos estaduais.

Dessa forma, com o propósito de conhecer os condicionantes da alocação de policiais militares nos presídios, foram realizados dois procedimentos estatísticos no SPSS: regressão logística e regressão linear ${ }^{4}$. No primeiro procedimento consideraram-se todas as unidades de análise e a variável dependente foi uma dummy ( $\mathrm{PM}$ ) com dois valores: 1 - com policial militar e 0 - sem policial militar. Os resultados indicaram as razões de chances de as unidades prisionais com certas características terem policiais militares, em relação aos estabelecimentos que não os possuíam; juntamente com as razões de chance de estabelecimentos com outras características não contarem com tais profissionais. No segundo procedimento utilizaram-se exclusivamente as prisões com policiais militares (com apenas $23 \%$ de ocorrência a

4. Regressão é uma técnica que permite explorar a relação de uma ou mais variáveis dependentes com uma ou mais independentes, ou explicativas. Enquanto a logística se aplica a variáveis dependentes binárias e determina o efeito que os coeficientes exercem sobre as chances de um evento ocorrer (ou de não ocorrer), utilizando-se do método da máxima verossimilhança, a regressão linear destaca o efeito de um conjunto de variáveis explicativas sobre determinado fenômeno representado por uma variável contínua (numérica) com mais de dois valores, valendo-se do método dos mínimos quadrados. 
QUADRO 1

Lista das Variáveis Independentes e das Suposiçôes em torno de Sua Relação com as Dependentes

\begin{tabular}{|c|c|c|}
\hline $\begin{array}{l}\text { CÓDIGO DA } \\
\text { VARIÁVEL }\end{array}$ & DESCRIÇÃO E TIPO & SuposiçÃo \\
\hline REGIÃo & $\begin{array}{l}\text { Região de localização: } \\
\text { Dummy, com os valores: } \\
1 \text { = Município da Região Metropolitana } \\
\text { (referente à capital ou a outras regiões); } \\
0=\text { Município do interior do estado. }\end{array}$ & $\begin{array}{l}\text { Os policiais militares estão mais presentes em presídios localizados } \\
\text { em municípios metropolitanos, pois é nas regiões metropolitanas } \\
\text { que se observam as taxas criminais mais elevadas e a presença de } \\
\text { coletivos criminais; e nelas os presos mais frequentemente residiam } \\
\text { antes de seu encarceramento. }\end{array}$ \\
\hline ТЕмро & $\begin{array}{l}\text { Tempo de existência, em anos, em relação } \\
\text { a 2016: } \\
\text { Contínua, logaritmo, com substituição dos } \\
\text { dados faltantes pela média. }\end{array}$ & $\begin{array}{l}\text { Quanto mais antigo o presídio, mais institucionalizado e diver- } \\
\text { sificado é o seu quadro de funcionários, incluindo, também, os } \\
\text { policiais militares. }\end{array}$ \\
\hline Presos & $\begin{array}{l}\text { Total de presos: } \\
\text { Contínua, logaritmo. }\end{array}$ & $\begin{array}{l}\text { Quanto maior a quantidade de presos, maior a demanda por um } \\
\text { quadro diversificado de servidores, inclusive de policiais militares. }\end{array}$ \\
\hline Presos-VAGa & $\begin{array}{l}\text { Presos por vaga: } \\
\text { Contínua, logaritmo. }\end{array}$ & $\begin{array}{l}\text { Quanto maior a superlotação prisional, maior a demanda por } \\
\text { policiais militares. }\end{array}$ \\
\hline FECHADO & $\begin{array}{l}\text { Exclusivamente regime fechado: } \\
\text { Dummy, com os valores: } \\
1 \text { = Só regime fechado; } \\
0=\text { Outros regimes. }\end{array}$ & $\begin{array}{l}\text { Instituições que possuem apenas o regime fechado necessitam } \\
\text { reforçar a vigilância; portanto, requerem mais policiais militares } \\
\text { do que aquelas com regime semiaberto, aberto ou misto. }\end{array}$ \\
\hline Provisórios & $\begin{array}{l}\text { Originalmente prevista para abrigar presos } \\
\text { provisórios: } \\
\text { Dummy, com os valores: } \\
1 \text { = Só presos provisórios, originalmente; } \\
0=\text { Condenados ou outras situações ju- } \\
\text { rídicas. }\end{array}$ & $\begin{array}{l}\text { As cadeias públicas ou outros estabelecimentos destinados a presos } \\
\text { provisórios (cujo desfecho processual muitas vezes é retardado) } \\
\text { são os que apresentam maiores problemas de insalubridade, super- } \\
\text { lotação e rebeliões. Assim, para reforçar o controle e a vigilância, } \\
\text { demandam policiais militares no quadro funcional. }\end{array}$ \\
\hline Masculino & $\begin{array}{l}\text { Presos do sexo masculino: } \\
\text { Dummy, com os valores: } \\
1=\text { Só para presos homens; } \\
0=\text { Só para presas ou mistos. }\end{array}$ & $\begin{array}{l}\text { Os presídios exclusivamente masculinos representam } 74 \% \text { do } \\
\text { total. Devido a sua magnitude, presume-se que contem com mais } \\
\text { policiais militares do que os exclusivamente femininos ( } 7 \% \text { ou } \\
\text { mistos }(17 \%) .(\text { Brasil, } 2017) \text {. }\end{array}$ \\
\hline TrÁFICO & $\begin{array}{l}\text { Percentual de prisões por tráfico de drogas sobre } \\
\text { o total de crimes: } \\
\text { Contínua, substituição dos dados faltantes } \\
\text { pela média. }\end{array}$ & $\begin{array}{l}\text { As condenações por tráfico de drogas vêm crescendo vertigino- } \\
\text { samente desde a promulgação da lei de drogas (Brasil, 2006). } \\
\text { Quanto maior é o número de presos por esse delito, maior será a } \\
\text { presença de policiais militares nas unidades prisionais, devido ao } \\
\text { recrudescimento da vigilância e à punição de fatos envolvidos com } \\
\text { o comércio ilegal de drogas em contextos de vulnerabilidade social. }\end{array}$ \\
\hline VISITAS & $\begin{array}{l}\text { Ocorrência de visitas aos presos: } \\
\text { Dummy, com os valores: } \\
1=\text { Com visitas, } 0=\text { Sem visitas. }\end{array}$ & $\begin{array}{l}\text { As prisões com regime fechado ou destinadas aos presos provisó- } \\
\text { rios requerem mais policiais militares e, por questão de segurança, } \\
\text { tendem a não estimular a visitação. } \\
\text { É a única variável para a qual se prevê uma relação assimétrica } \\
\text { com a dependente. }\end{array}$ \\
\hline SERV_PRESO & $\begin{array}{l}\text { Razão entre os outros servidores (administra- } \\
\text { tivos, técnicos da área da saúde e educação, ad- } \\
\text { vogados etc., excluídos os agentes penitenciários } \\
\text { e policiais civis e militares) e o total de presos: } \\
\text { Contínua, logaritmo. }\end{array}$ & $\begin{array}{l}\text { Quanto mais diversificado é o quadro de pessoal, maiores serão a } \\
\text { demanda por e a presença de policiais militares. }\end{array}$ \\
\hline
\end{tabular}

Fonte: Elaboração própria. 
variável percentual de policiais militares não apresentou distribuição normal, o que justifica a exclusão, nesta análise, das unidades prisionais sem policiais militares), para verificar as características dos presídios relacionadas com a alocação de um maior ou menor número desses profissionais, ou seja, a intensidade da presença de policiais militares, tomando-se como variável dependente a razão entre a quantidade de policiais militares e o número de $\operatorname{presos}^{5}$ (PM_PRESO).

As dez variáveis independentes (cinco dummy e cinco contínuas) ${ }^{6}$ e as suposições preliminares quanto aos resultados esperados aparecem no quadro a seguir.

Com as suposições apresentadas e realizados os procedimentos de análise multivariada no software estatístico, foram encontrados os resultados dispostos na tabela 1 , subsequente.

Os resultados mostram, em primeiro lugar, que o modelo da regressão linear apresentou maior poder explicativo, com um $\mathrm{R}^{2}$ (Adjusted $R$ Square ${ }^{7}$ ) de $65 \%$ contra $35 \%$ da regressão logística $\left(\text { Nagelkerke } R^{2}\right)^{8}$. Todavia, considerando-se os valores de significância maiores ou iguais a 0,05 , no primeiro modelo exposto na tabela verifica-se um maior número de variáveis preditivas - sete - em relação ao segundo modelo, com apenas três fatores.

Também se verifica que, ao contrário do esperado, duas variáveis não contribuíram ou pouco explicaram a variância em ambos os modelos; são elas: percentual de prisões por tráfico de drogas e região de localização do presídio. Ou seja, as prisões com policiais militares ou com maior quantidade deles são aquelas onde não predomina um tipo delitivo e que se espalham pelo território estadual, não se concentrando nas regiões metropolitanas.

Em contrapartida, o fator mais influente nas duas regressões foi a razão entre outros profissionais (exceto policiais civis e militares e agentes penitenciários) e o número de presos. Na regressão logística essa variável aumentou em 23 vezes (vide o

5. Foi utilizado esse indicador porque não estavam disponibilizadas no Infopen as informações sobre o número de "servidores em atividade de custódia" ou agentes penitenciários em cada unidade prisional, o que inviabilizou o cálculo do total de funcionários, por meio da soma dos diferentes cargos.

6. Ressalta-se que foram realizados testes (correlações bivariadas) para evitar a alta colinearidade entre as variáveis independentes, nos quais se constatou que os coeficientes de correlação de Pearson eram inferiores a 0,600 .

7. $R$-square é o coeficiente de determinação que mostra o quanto da variável dependente é explicado pelo modelo de regressão, assumindo valores entre 0 e 1 que são transformados em percentuais. Em regressões múltiplas, com mais de uma variável independente, utiliza-se o coeficiente de determinação ajustado (Adjusted $R$ Square), cujos valores devem se aproximar do primeiro coeficiente, caso contrário é possível que existam variáveis independentes inadequadas e pouco influentes.

8. Nagelkerke R2 é uma adaptação do Cox-Snell R2, ambos são testes utilizados em regressões logísticas, comparáveis ao R2 da regressão linear. O primeiro coeficiente indica quanto das variações das razões de chance são explicadas pelo modelo, assumindo valores entre 0 e 1 que são transformados em percentuais. 
TABELA 1

Sintese dos Resultados das Regressões

\begin{tabular}{|c|c|c|}
\hline $\begin{array}{l}\text { VARIÁVEIS } \\
\text { EXPLICATIVAS }\end{array}$ & $\begin{array}{l}\text { Regressão logística } \\
\mathrm{N}=1.268 \\
\text { Dependente }=>\text { PM (Presença ou não de } \\
\text { policial militar, dummy) } \\
\mathbf{0 , 2 3 4}\left(\text { Nagelkerke } \mathrm{R}^{2}\right)\end{array}$ & $\begin{array}{l}\text { Regressão Linear } \\
\mathrm{N}=297 \\
\text { Dependente => PM_PRESo (Razão entre o número } \\
\text { de policiais militares e o de presos, contínua) } \\
\mathbf{0 , 6 5 4} \text { (Adjusted R. Square) }\end{array}$ \\
\hline & Significância e $\operatorname{Exp}(B)$ & Significância e Beta \\
\hline REgião & $\begin{array}{c}0,350 \\
0,845(16 \%)\end{array}$ & $\begin{array}{r}0,733 \\
-0,013\end{array}$ \\
\hline Темро & $\begin{array}{l}0,025 \\
1,548\end{array}$ & $\begin{array}{l}0,358 \\
0,033\end{array}$ \\
\hline Presos & $\begin{array}{l}0,000 \\
2,293\end{array}$ & $\begin{array}{c}0,015 \\
-0,142\end{array}$ \\
\hline Presos-VAGA & $\begin{array}{l}0,091 \\
1,630\end{array}$ & $\begin{array}{l}0,020 \\
-0,097\end{array}$ \\
\hline FECHADO & $\begin{array}{l}0,001 \\
2,356\end{array}$ & $\begin{array}{l}0,426 \\
0,041\end{array}$ \\
\hline Provisórios & $\begin{array}{l}0,000 \\
3,875\end{array}$ & $\begin{array}{l}0,071 \\
0,096\end{array}$ \\
\hline Masculino & $\begin{array}{l}0,013 \\
1,599\end{array}$ & $\begin{array}{l}0,297 \\
0,011\end{array}$ \\
\hline TRÁfico & $\begin{array}{l}0,330 \\
2,216\end{array}$ & $\begin{array}{l}0,065 \\
-1,849\end{array}$ \\
\hline VISITAS & $\begin{array}{c}0,000 \\
0,497(50 \%)\end{array}$ & $\begin{array}{r}0,061 \\
-1,883\end{array}$ \\
\hline SERV_PRESO & $\begin{array}{c}0,000 \\
23,049\end{array}$ & $\begin{array}{l}0,000 \\
0,625\end{array}$ \\
\hline
\end{tabular}

Nota: Os resultados estatisticamente significativos aparecem em negrito. (legenda)

Fonte: Elaboração própria.

coeficiente que indica as razões de chance, o $\operatorname{ExpB}$ ) as chances de a unidade prisional contar com policiais militares, e na regressão linear ela alcançou um Beta ${ }^{9}$ de 0,625 , demonstrando que o valor da razão entre policiais militares e o número de presos (PM_preso) aumenta com a existência de outros profissionais, isto é, com um quadro funcional diversificado, com cargos administrativos, técnicos da área da saúde e

9. Beta é coeficiente estimado e padronizado do modelo de regressão, que mostra quanto muda na variável dependente cada medida da independente. A sua padronização é necessária porque as variáveis independentes têm escalas, desvios-padrão e médias muito distintas. 
educação e advogados. Com a ressalva de que não foram contemplados nas análises os agentes penitenciários (o grupo mais numeroso), por inacessibilidade deste dado.

Especificamente quanto à regressão logística, as seguintes outras variáveis aumentaram as chances da presença de policiais militares, mas com um peso bastante inferior em relação à primeira mais influente: presos provisórios (em 3,875 vezes); regime fechado (em 2,356 vezes); total de presos (em 2,293 vezes); presídios masculinos (em 1,599 vezes) e o tempo de existência do estabelecimento (em 1,548 vezes). Apenas uma variável reduziu em $50 \%$ as chances da existência de policiais militares: a ocorrência de visitas, que também apresentou sinal negativo na regressão linear, mas com significância um pouco superior à prevista, de 0,061. Outra variável - além de Região e tráfico de drogas - também não repercutiu nas chances de o presídio possuir policiais militares: presos por vaga. Portanto, tendem a não serem superlotados os presídios com policiais militares.

Quanto à regressão linear, as outras duas variáveis que influenciaram, em sentido negativo e de forma não esperada, foram: o total de presos (Beta $=-0,142)$ e o número de presos por vaga (Beta $=-0,097)$. Isso demonstra que nenhuma das duas variáveis amplia a quantidade de policiais militares em relação ao número de presos naqueles presídios onde eles se fazem presentes. As outras variáveis sem influência no segundo modelo foram: tempo de existência, regime fechado, destinado a presos provisórios e presídio masculino.

\section{Considerações finais}

Este trabalho examinou a presença de policiais militares nos presídios brasileiros, processo aqui denominado de militarização. Ela atinge 297 (23\%) do total de unidades prisionais e está presente em dezoito estados brasileiros, com maior frequência no Piauí, Rio Grande do Norte, Ceará, Amazonas, Pernambuco, Paraíba, Rio Grande do Sul, Roraima, Bahia e Acre. Os policiais militares prevalecem onde há menor presença de agentes penitenciários, o que denota uma tendência de estes profissionais assumirem outras funções dentro dos presídios, concernentes com o controle interno e a administração prisional, para além da mera vigilância externa.

Entre as características das unidades prisionais que estão relacionadas com a presença maior ou menor dos policiais militares, e que podem indicar certa preferência dos governos estaduais por esta diretriz de contratação e alocação de pessoal em sua política penitenciária, estão: a) quanto à presença de policiais militares: quantidade de outros profissionais em relação ao número de presos; estabelecimentos destinados a presos provisórios ou que cumprem pena em regime fechado; com maior número de presos e exclusivamente masculinos; b) quanto à intensidade da participação 
(razão entre o número de policiais militares e o de presos): quantidade de outros profissionais em relação ao número de presos (aumenta); total de presos e superlotação (diminuem). O resultado díspar em relação ao total de presos (faz crescerem as chances de o presídio contar com policiais militares versus diminui a sua quantidade) denota que os presídios maiores têm relativamente menos policiais militares do que os menores. Nos primeiros eles provavelmente tendem a ser alocados nas atividades tradicionais de vigilância externa, sinalizando a preferência de alguns governos estaduais em utilizarem funcionários civis lotados nos órgãos penitenciários no quadro funcional dos presídios, ao mesmo tempo que procuram manter os policiais militares em suas atividades corriqueiras de policiamento e controle da ordem pública.

Quanto à prisionização (Clemmer, 1940) e ao estigma social associado à atuação dos funcionários prisionais, em especial dos agentes penitenciários (Lourenço, 2010), presume-se que tais aspectos não se aplicam integralmente aos policiais militares, uma vez que eles possuem uma identidade profissional própria vinculada ao uso da força e da arma de fogo e aos princípios organizacionais de hierarquia e disciplina, que a distingue da do "carcereiro". Supõe-se que tal identidade profissional não seja abalada quando os policiais atuam nas prisões. De outro lado, constata-se uma valorização das polícias dentro do campo penitenciário, evidenciada na denominação de "polícias penais" na emenda constitucional recém-aprovada (Brasil, 2019), bem como na imagem positiva do trabalho policial incorporada por agentes penitenciários que ressaltaram gostar de atuar como polícia (Sabaini, 2009, p. 26).

Conclui-se este trabalho salientando-se a importância de serem ampliados os estudos sobre atores prisionais para além do grupo de presos, em especial sobre o conjunto dos servidores penitenciários. Conforme constatado, os poucos estudos existentes sobre os trabalhadores das prisões centram-se nos agentes penitenciários, a categoria mais numerosa (74\%), em detrimento dos restantes $26 \%$. Reside aí a contribuição deste estudo, que, ao analisar por meio de uma metodologia quantitativa abrangente a participação dos policiais militares entre os servidores penitenciários de todo o Brasil, instiga a reflexão sobre as continuidades e as mudanças das políticas penitenciárias estaduais. 


\section{Referências Bibliográficas}

Bauman, Zygmunt. (1999), Globalização: as consequências humanas. São Paulo, Jorge Zahar, pp. 111-136.

Brasil. (1984), Lei Federal n. 7.210, de 11 de junho de 1984. Institui a Lei de Execução Penal. Brasília.

Brasil. (2003), Lei n. 10.826, de 22 de dezembro de 2003. Dispõe sobre registro, posse e comercialização de armas de fogo e munição, sobre o Sistema Nacional de Armas - Sinarm, define crime e dá outras providências. Brasília.

Brasil. (2006), Lei Federal n. 11.343, de 23 de agosto de 2006. Institui o Sistema Nacional de Políticas Públicas sobre Drogas [...]. Brasília.

Brasil. (2014), Lei Federal n. 12993, de 17 de junho de 2014. Altera a Lei no 10.826, de 22 de dezembro de 2003, para conceder porte de arma funcional. Brasília.

Brasil. (2016), Levantamento Nacional de Informaçôes Penitenciárias (Infopen). Base de dados 2016. Brasília, Ministério da Segurança Pública. Disponível em http://depen.gov.br/DE$\mathrm{PEN} /$ depen/sisdepen/infopen/bases-de-dados/bases-de-dados, consultado em 31/10/2018.

Brasil. (2017), Levantamento Nacional de Informaçôes Penitenciárias (Infopen). Relatório Sintético [referente às informações de 2016]. Brasília, Ministério da Segurança Pública.

Brasil. (2019), Emenda Constitucional n. 104. Altera o inciso XIV do caput do art. 21, o $\$ 4^{\circ}$ do art. 32 e o art. 144 da Constituição Federal, para criar as polícias penais federal, estaduais e distrital. Brasília: Congresso Nacional.

Chies, Luiz A. Bogo (coord.); Barros, Ana Luísa X.; Lopes, Carmem L. A. da S. \& OliveiRA, Sinara F. (2001), A prisionalização do agente penitenciário: um estudo sobre encarcerados sem pena. Pelotas, Educat.

Clemmer, Donald. (1940), The prison community. Nova York: Rinehart \& Co.

Coelro, Edmundo Campos. (1987), A oficina do diabo: crise e conflito no Sistema Penitenciário do Rio de Janeiro. Rio de Janeiro, Instituto Universitário de Pesquisas do Rio de Janeiro.

Coelho, Edmundo Campos. (2005), A oficina do diabo e outros estudos sobre a criminalidade. Rio de Janeiro, Record.

Ferreira, Sandra A. \& Sousa, Bárbara R. de. (2015), "O sentido do trabalho na representação social de agentes penitenciários do sistema prisional tocantinense”. Trabalho apresentado no vi Cipsi - Congresso Internacional de Psicologia da UEM. Maringá/PR, Universidade Estadual de Maringá, 19 a 22 de maio.

Foucault, Michel. ([1975] 1986), Vigiar e punir: nascimento da prisão. Petrópolis, Vozes.

GARLAND, David. (2008), A cultura do controle: crime e ordem na sociedade contemporânea. Rio de Janeiro, Instituto Carioca de Criminologia/Revan.

Goffman, Erving. (1974), Manicômios, prisões e conventos. São Paulo, Perspectiva.

Jaskowiak, Caroline \& Fontana, Rosane T. (2015), "O trabalho no cárcere: reflexões 
acerca da saúde do agente penitenciário". Revista Brasileira de Enfermagem-Reben, Brasília, 68 (2): 235-243.

Lemgruber, Julita. (1983), Cemitério dos vivos: análise sociológica de uma prisão de mulheres. Rio de Janeiro, Forense.

Lopes, Rosalice. (2002), "Psicologia jurídica, o cotidiano da violência: o trabalho do agente de segurança penitenciária nas instituições prisionais". Psicologia para América Latina. Disponível em http://pepsic.bvsalud.org/scielo.php?script=sci_arttext\&pid=S1870-350X20 02000100004\&lng=pt\&nrm=iso.

Lopes, Rosalice. (1998), Atualidades do discurso disciplinar: a representação da disciplina e do disciplinar na fala dos agentes de segurança penitenciária. São Paulo, dissertação de mestrado, PPG Psicologia Escolar e do Desenvolvimento Humano da Universidade de São Paulo.

Lourenço, Luiz Claudio. (2010), “Batendo a tranca: impactos do encarceramento em agentes penitenciários da Região Metropolitana de Belo Horizonte”. Dilemas, 3 (10): 11-31.

Lourenço, Luiz Claudio \& Alvarez, Marcos César. (2017), "Estudos sobre prisão: um balanço do estado da arte nas ciências sociais nos últimos vinte anos no Brasil (1997-2017)". Revista Brasileira de Informação Bibliográfica em Ciências Sociais - BIB, 84 (2): 216-236.

Monteiro, L. (2013), A permeabilidade das grades na busca cotidiana pela ordem: um estudo sobre agentes penitenciários em Salvador, BA. Salvador, dissertação de mestrado em Ciências Sociais, Universidade Federal da Bahia.

Moraes, Pedro Rodolfo Bodê de. (2013), "A identidade e o papel de agentes penitenciários". Tempo Social - Revista de Sociologia da USP, 25 (1): 131-147. Disponível em https://doi. org/10.1590/S0103-20702013000100007.

Moraes, Pedro Rodolfo Bodê de. (2005), Punição, encarceramento e construção de identidade profissional entre agentes penitenciários. São Paulo, IBCCRIM.

Ramalho, José Ricardo. (1979), O mundo do crime: a ordem pelo avesso. São Paulo, Graal.

REIS, M. P. (2012), Entre o poder e a dor: representações sociais da corrupção e da violência no sistema penitenciário de São Paulo. Brasília, tese de doutorado em Sociologia, Universidade de Brasília.

Rudnicki, Dani. (1999), “Prisão, Direito Penal e respeito pelos direitos humanos”. In: TAvares Dos Santos, José Vicente (org.). Violência em tempo de globalização. São Paulo, Hucitec, pp. 544-570.

SABAINI, Raphael T. (2012), Uma cidade entre presídios: ser agentepenitenciário em Itirapina-SP.

São Paulo, dissertação de mestrado em antropologia social, Faculdade de Filosofia, Letras e Ciências Humanas da Universidade de São Paulo.

SABAINI, Raphael T. (2009), "Agentes penitenciários de Itirapina, SP: identidade e hierarquia”. Ponto Urbe [online]: Revista do Núcleo de Antropologia Urbana da USP, 5: 1-13.

Salla, Fernando A. (2017), "Vigiar e punir e os estudos prisionais no Brasil”. Dilemas, 2: 29-43. Disponível em https://revistas.ufrj.br/index.php/dilemas/article/view/14201. 
Santos, José R. R. (2007), O fenômeno da prisionização em agentes penitenciários do estado do Paraná. Curitiba/PR, monografia, Curso de Pós-graduação em Gestão penitenciária, Universidade Federal do Paraná.

Sarmento, V. A. (2014), Análise do curso preparatório para agentes de segurança penitenciária femininas e sua relação com a formação em Direitos Humanos. João Pessoa, dissertação de mestrado em Direitos Humanos, Universidade Federal da Paraíba.

Silveira, Joslei T. (2009), “'Se tirar o colete não dá pra saber quem é preso, quem é agente’: trabalho, identidade e prisionização". Anais do I Seminário Nacional Sociologia e Política, Curitiba, Universidade Federal do Paraná.

Siqueira, I. B. L. (2016), "Aqui ninguém fala, escuta ou vê": relatos sobre o cotidiano profissional dos agentes de segurança penitenciária em Manaus. Manaus, dissertação de mestrado em Sociologia, Universidade do Amazonas.

Thompson, Augusto. (1980), A questão penitenciária. Rio de Janeiro, Forense.

Universidade de São Paulo, Núcleo de Estudos da Violência, Comissão Teotônio Vilela. (1995), “II - Prisões no Brasil". In: Os Direitos Humanos no Brasil. São Paulo, UsP, pp. 125-126.

Wacquant, Loic. (2001), "Do Estado-Providência ao Estado-Penitência: realidades norte-americanas, possibilidades europeias”. In: WACQUAnt, Loic. As prisões da miséria. Rio de Janeiro, Jorge Zahar, pp. 77-151.

World Prison Brief. (2016), Disponível em http://www.prisonstudies.org, consultado em $2 / 1 / 2019$.

Zaffaroni, Eugenio Raúl. (1991), “La filosofía del sistema penitenciario en el mundo contemporâneo”. In: Beloff, Mary Ana; Bovino, Alberto \& Courtis, Christian. (orgs.). Cuadernos de la Cárcel. Buenos Aires, [s.ed.], pp. 36-62.

\section{Resumo}

A militarização dos presídios brasileiros

Este trabalho analisa a presença de policiais militares nos presídios brasileiros, a sua distribuição nas unidades federativas e as principais características dos estabelecimentos onde eles atuam. Além de revisão bibliográfica, a metodologia abrangeu estatística descritiva e análise de regressão, com base em informações do Levantamento Nacional de Informações Penitenciárias. Constatou-se que os policiais militares atuam em $23 \%$ dos presídios e em dezoito estados brasileiros. Entre as características das prisões onde esses profissionais estão presentes destacam-se: têm um quadro mais diversificado de servidores, não apresentam superlotação e registram menor número de visitas aos presos.

Palavras-chave: Prisões; Funcionários prisionais; Policiais militares; Militarização; Brasil. 


\section{Abstract}

\section{The militarization of Brazilian prisons}

This paper analyzes the presence of military police in Brazilian prisons, their distribution in the federal units and the main characteristics of the establishments where they operate. In addition to a bibliographic review, the methodology covered descriptive statistics and regression analysis, based on information from the National Penitentiary Information Survey. It was found that military police act in $23 \%$ of prisons and in 18 Brazilian states. Among the characteristics of the prisons where these professionals are present, the following stand out: they have a more diversified staff, do not have overcrowding and register fewer visits to prisoners.

Keywords: Prisons; Prison officials; Military police; Militarization; Brazil.

Texto recebido em 16/4/2019 e aprovado 19/9/2019.

DOI: 10.11606/0103-2070.ts.2020.156940.

Leticia Maria Schabbach é professora do Departamento de Sociologia da Universidade Federal do Rio Grande do Sul.E-mail: leticiams65@gmail.com. 